\title{
Influence of Dual Task Training in Indoor Versus Outdoor Environment on Physical Function and Social Activity among Elderly.
}

\author{
S. Anandh ${ }^{1}$, G. Varadharajulu ${ }^{2}$, Mahendra M. Alate ${ }^{3}$ \\ ${ }^{1}$ Professor \& HOD, Physiotherapy in Community Health Sciences, ${ }^{2}$ Dean, Faculty of Physiotherapy, \\ ${ }^{3}$ Statistician, Director of Research Office, Krishna Institute of Medical Sciences Deemed to be University, Karad
}

\begin{abstract}
The existential reality of elderly is that their physical efficiency is challenged as per their changes in living environment and degree of socialization. Numerous elements of every task performed unconsciously to intervene dual task (cognitive $\&$ motor or motor $\&$ motor) and so dual task activity training is essential.
\end{abstract}

Aim: To find the influence of dual task activity training in indoor versus outdoor environment on physical activity and social activity self-efficacy measure among elderly.

Objectives: a) To study the influence of dual task training in indoor environment on physical function \& social activity self-efficacy measures among elderly. b) To study the influence of dual task training in outdoor environment on physical function \& social activity self-efficacy measures among elderly. c) To compare the influence of dual task training in indoor \& outdoor environment on physical function \& social activity self-efficacy measures among elderly.

Material and Method: Group A subjects were treated in indoor (closed) environment and Group B subjects were treated in outdoor (open) environment with 38 subjects under each group. The duration of training intervention in each group is 60 minutes per session of exercise program including warm up \& cool about period administered twice per week for 12 weeks duration. The pre-test measures was recorded on the first day at the start of treatment and the post-test measures after 12 weeks duration from the start of intervention for statistical analysis.

Results: The study predicted significant results of outdoor dual task activity with relation to timed 10 meter walk test promoting physical function and motivation to participate in social activities.

Keywords: Indoor Environment, Outdoor Environment, Dual Task activity, Functional Performance.

\section{Introduction}

Need of Geriatric Research and Public Health

Need: The extent of adaptation towards their lifestyle

\section{Corresponding Author:}

\section{Dr. S. Anandh}

Professor \& HOD, Physiotherapy in Community health sciences, Krishna collage of Physiotherapy, KIMSDU, Karad (Maharashtra) 415110 India. Phone No.:

9373911624

e-mail: anandh73@gmail.com changes,social participation and environment in which elderly perform their physical activities needs to be understood properly ${ }^{1,2}$. The existential reality is that their efficiency in physical capacity needs are challenged as per their changes in living environment and degree of socialization.

The Nature of Dual Task Activity and Research Need: Numerous elements of tasks unconsciously intervene dual task. The transfer of training effects of/on daily needs is a challenge and so it needs to be practiced in both indoor and outdoor to prevent incomplete training with regard to fall prevention ${ }^{3}$. 
Environmental Influence on Functional Performance in Elderly: Independent living among elderly comes with the belief when their cop abilities of self-care in the prevailing environment and completing tasks avoiding support ${ }^{4}$.

Environmental Influence on Social Participation on Elderly: Social participation is meant to be a key dimension of healthy successful aging. The elderly needs to manage the distracting factors of environment to achieve the feeling of steadiness to enhance participation in instrumental activities of daily life, which lets an individual to live more independently in the community with good mobility ${ }^{5}$.

Summarized Literature Review: Perfect tracking of the performance of dual task activity and estimating the individual's progression is the basic requirement of methodology. Several studies are done pertaining to specific activity at indoor and outdoor environment. Older studies are found significant where the elderly enjoy and participate in involvement in physical activities which specifies regarding fear avoidance behavior had positive results. All relevant studies since 2005 had been considered to predict the research gap ${ }^{6,7}$. There exists lack of studies with relation to environmental influences, with respect to indoor and outdoor training respectively.

Need of The Study: Attention and working memory seems to coincide during any task performance ${ }^{3}$. The processing of information about/on holding two ideas in mind until completion of dual task within a brief period of attention stimulus in a given environmental situation is the normal physiological criteria to be met with. The individual preferences for the elderly and their comfort needs have to be valued during any form into physical activity training.

Material and Method: The research is an interventional study, pre - post study design with a sample size of 76 subjects utilizing random sampling method and the period of study was one Year. Inclusion criteria : All asymptomatic elderly, above the age of 65 years including both genders; retired senior citizens restricted to their residence most of the time; no history of fall for the past 12 months; ability to walk $20 \mathrm{~m}$ without human assistance; ability to speak/read/ communicate . Exclusion criteria : Medically unstable patients and patients with pacemaker; chronic illness \& life threatening medical issues; all types of disabilities; uncooperative and psychiatric elderly patients; patients with paralytic limbs, vestibular dysfunction; subjects who are doing part time work, farm work or any other regular work are restricted from the study.

Outcome Measures: The pre - test \& post - to test measures includes the following. 1. Timed 10-Meter walk Test 2. Timed Up \& Go Test 3. Social Activity Self - Efficacy Measure.

Procedure: Group A subjects were treated in indoor (closed) environment and Group B subjects were treated in outdoor (open) environment with 38 subjects under each group. Intervention in each group is 60 minutes exercise program including warm up \& cool about administered twice per week for 12 weeks duration ${ }^{9}$. The pre-test and post-test measures was recorded on the first day at the start of treatment and post 12 weeks duration . The results recorded were considered for statistical analysis using Mean, standard deviation and unpaired $t$ test to compare two independent groups.

Exercise Procedure: 1. Jacobson's relaxation: 05 minutes. 2. Free exercises in extremities and spine: 05 minutes. 3. Personal activities (Folding Bed sheet/ counting currency \& Dressing self): 10 minutes. 4. Cognitive exercises (Loud reading, Writing/Drawing while listening to music \& Brushing teeth with nondominant hand): 10 minutes. 5. Dual task activity duration: 20 minutes (which includes reading/talking while walking: 05 minutes; follow the light/cues while walking: 05 minutes; obstacle walking: 10 minutes) 6 . Recreational activity (catching \& throwing ball): 05 minutes. 7. Relax breathing exercises: 05 minutes.

\section{Results}

Table No: 1: Comparison of social activity selfefficacy measures: Posttest result measures of indoor versus outdoor dual task activity training.

\begin{tabular}{|l|c|c|}
\hline \multirow{2}{*}{ Social activity } & \multicolumn{2}{|c|}{ Social activity self-efficacy measure } \\
\cline { 2 - 3 } & $\begin{array}{c}\text { Indoor } \\
\text { (Group A) }\end{array}$ & $\begin{array}{c}\text { Outdoor } \\
\text { (Group B) }\end{array}$ \\
\hline Mean & 50.08 & 44.42 \\
\hline Standard Deviation & 9.030 & 7.354 \\
\hline p value & \multicolumn{2}{|c|}{0.0037} \\
\hline t value & \multicolumn{2}{|c|}{2.995} \\
\hline
\end{tabular}

Note: The Post-test result measures of Indoor versus Outdoor Dual task activity training in relation to social activity self-efficacy measures/measured is significant as $\mathrm{p}$ value is less than $0.05(<0.05)$. 
Table No: 2 Comparison of timed 10 meters walk to test: Posttest result measures of indoor versus outdoor dual task activity training.

\begin{tabular}{|l|c|c|}
\hline \multirow{2}{*}{ Physical activity } & \multicolumn{2}{|c|}{ Timed 10 meter walk test } \\
\cline { 2 - 3 } & $\begin{array}{c}\text { Indoor } \\
\text { (Group A) }\end{array}$ & $\begin{array}{c}\text { Outdoor } \\
\text { (Group B) }\end{array}$ \\
\hline Mean & 15.39 & 14.48 \\
\hline Standard Deviation & 1.621 & 1.569 \\
\hline p value & \multicolumn{2}{|c|}{0.0151} \\
\hline t value & \multicolumn{2}{|c|}{2.488} \\
\hline
\end{tabular}

The Post-test result measures of Indoor versus Outdoor Dual task activity training in relation to timed 10 meter walk test is significant as $\mathrm{p}$ value is less than $0.05(<0.05)$.

Table No: 3 Comparison of timed up and go to test: Posttest result measures of indoor versus outdoor dual task activity training.

\begin{tabular}{|l|c|c|}
\hline \multirow{2}{*}{ Physical activity } & \multicolumn{2}{|c|}{ Timed Up and Go test } \\
\cline { 2 - 3 } & $\begin{array}{c}\text { Indoor } \\
\text { (Group A) }\end{array}$ & $\begin{array}{c}\text { Outdoor } \\
\text { (Group B) }\end{array}$ \\
\hline Mean & 13.16 & 12.90 \\
\hline Standard Deviation & 1.28 & 1.003 \\
\hline p value & \multicolumn{2}{|c|}{0.3378} \\
\hline$t$ value & \multicolumn{2}{|c|}{0.9649} \\
\hline
\end{tabular}

The Post-test result measures of Indoor versus Outdoor Dual task activity training in relation to timed up and go to test is not significant as $\mathrm{p}$ value is greater than $0.05(>0.05)$. The statistical values is found significant in dual task activity training in outdoor environment with unpaired-t test for timed $10 \mathrm{~m}$ walk test and social activity self-efficacy measure since the $\mathrm{p}$ value is less than $0.05(<0.05)$. The statistical values are found not significant in dual task activity training in outdoor environment with unpaired-t test for timed up and go test since the $\mathrm{p}$ value is greater than $0.05(>0.05)$.

\section{Discussion}

To promote worthy independent living, therapeutic interventions in elderly should involve dual task activity stimulating sensory acuity ${ }^{10,11}$. They should be well trained progressively in sudden stimulus driven activities in different environments for successful dual task activity performance and thereby preventing falls.

The 10 meter walk test has previously been used

to describe differences in walking speed across the lifespan demonstrating that speed begins to decline by 50 years of age and continues to decrease to each progressive decade of life. Elderly who spend more time for outdoor environment are said to be physically active, walk longer distance than those who spend more time indoor environment. Thus there will be reduced risk of morbidity specifically, if they walk for longer distance as possible in outdoor environment.

Infrequent performance of outdoor walking has been proved as a marker for frailty and can increase the risk of morbidity \& self-care declines to result in social isolation. In this study, the elderly were trained in an outdoor natural environment under supervision without risky additional barriers like sloppy surface, uneven terrain, traffic areas, noisy environment, etc., due to continuation of their participation ensuring safety. Dual task training is a therapeutic approach which has improved outdoor walking skills in elderly.

The results predict that social activity self-efficacy is significant which implies safe participation in physical activities indirectly. The results signify that outdoor environment is preferable to improve interest or pleasure in performing dual task activities. So, it enhances the physical activity participation in elderly. The higher degree of performance and practice of dual task activity training in outdoor environment makes them fitter with control over any environment preventing falls. Till date only few studies has examined the interactive effects of exercise and mood in older cohorts and so further research work is in need to elderly wellness ${ }^{12}$.

The transformative exercise framework supports rehabilitation to wellness of elderly that emphasizes a linkage between many health professionals. The focus areas are rehabilitation, condition-specific exercise, fitness and lifetime physical activity emphasizing a range of options for promoting safe activities among elderly.

All participants that participated in the outdoor environment training had felt a comfort zone and positive physical ability in walking 10 meters and felt repeating it often. Even though the elderly showed performance variations in each session to a limit, it was found that outdoor environment were suitable for a greater extent. It is usual that elderly individuals modify the walking speed and balance control as per their fall related selfefficacy and fear factors to suit different environmental condition ${ }^{8}$. Dual task activity training performed in 
outdoor environment allows the elderly to engage themselves in challenging situations and adjusting to the environment in completing the task successfully. At the end of 12 weeks protocol it's found that the performance of timed 10 meters/metered to walk to test has proved significant in outdoor training compared to indoor training which implies the need of preferable training environment to overcome barriers related to fall prevention. Natural environment creates a confidence promoting sensory awareness and cognition as felt by the elderly. In addition the better performance in outdoor environment can be utilized as a cost-effective and interest provoking method of physical activity training in elderly.

There exists clinical evidence that dual task activity training for elderly with mild to moderate form of delirium requires to be trained in simulated environment and outdoors ${ }^{9}$. The invention of park fitness, big outdoor gyms for elderly is expanding with the initiation for promoting wellness for the elderly.

The "Timed up and go test" (TUG) are designed to measure basic mobility function. Limited equipment is required and very cost effective test which is therefore convenient in any form of clinical settings. As the timed up and go to test has many components which need stability, attention, uniform speed of performance, turning and changing positions the elderly found comfortable with performing in a safe indoor environment. It denotes some type of physical activity training is required in indoor environment too. Majority of the elderly have some difficulty in using foot wear comfortably or some minor physiological drop exists which was a considerable factor of non-significant result of relation to timed up and go to test. Early mobility deficit was found among most of the elderly which consistently improved on practice and duration. This has been found as a reason for non-significant results of relation to time up and go to test.

The reduced duration of completing 10 meters walking distance between outdoor environments signifies that the physiological symptom of perceived exertion was lower when compared to participants trained under indoor environment ${ }^{9,12}$. There is significant evidence and this study provides additional weightage that there is long term functional health benefits of elderly exposed to outdoor environment training regularly. Thus the significant outcome of the study stands as a facilitator for the elderly who resists moving to outdoor environment due to any possible reason for special consideration to gender.

The significant results of self-efficacy in social activity imply that it is a positive predictor for improving physical activity. This will influence the instrumental activities of daily living in a long run promoting outdoor activity $^{13}$. In a nutshell, we can conclude that the dual task training brings back a lost skill.

Feedback of Subjects: 1. Easier and interested to perform exercises/participation in progressive physical activity in the absence of therapists. 2. Dual task activity training found to improve communication/improves/ improved participation in instrumental activities and reduce fear factor. 3 . Able to acknowledge $\&$ react to the physical demands as per progression ${ }^{13}$.

Clinical Implications: 1. The patient has to recognize that his recovery and functional status is largely the result of his own efforts and utilizing his senses in a relaxed environment. 2. It focuses on the role of physiotherapists in addressing specific physical fitness needs of those at risk of falls ${ }^{15}$.

\section{Conclusion}

The study predicted significant results of outdoor dual task activity in promoting physical function of timed 10 meter walk test and motivation to participate in social activities. In spite of the performance limits, the participants expressed that the natural feelings of outdoor environment (climate, mild sound, mixed visual stimulus in outdoor) were never experienced as distraction interrupting the training ${ }^{14,16}$.

Ethical Issue: Ethical clearance was takenfrom institutional ethical committee, KIMSDU, Karad.

Funding Sources: Krishna Institute of Medical Sciences Deemed To Be University, Karad.

\section{Conflict of Interest: Nil}

\section{Reference}

1. Frenk J, Chen L, Bhutta ZA, Cohen J, Crisp N, Evans T, Fineberg H, Garcia P, Ke Y, Kelley P, Kistnasamy B. Health professionals for a new century: transforming education to strengthen health systems in an interdependent world. The lancet. 2010 Dec 4;376(9756):1923-58.

2. Rimmer J, Lai B. Framing new pathways in 
transformative exercise for individuals with existing and newly acquired disability. Disability and rehabilitation. 2017 Jan 16;39(2):173-80.

3. Perkins JM, Multhaup KS, Perkins HW, Barton C. Self-efficacy and participation in physical and social activity among older adults in Spain and the United States. The Gerontologist. 2008 Feb 1;48(1):51-8.

4. Brustio PR, Rabaglietti E, Formica S, Liubicich ME. Dual-task training in older adults: The effect of additional motor tasks on mobility performance. Archives of gerontology and geriatrics. 2018 Mar 1;75:119-24.

5. Wollesen B, Schulz S, Seydell L, Delbaere K. Does dual task training improve walking performance of older adults with concern of falling?. BMC geriatrics. 2017 Dec;17(1):213.

6. Reelick MF, van Iersel MB, Kessels RP, Rikkert MG. The influence of fear of falling on gait and balance in older people. Age and ageing. $2009 \mathrm{Jul}$ 1;38(4):435-40.

7. Silsupadol P, Shumway-Cook A, Lugade V, van Donkelaar P, Chou LS, Mayr U, Woollacott MH. Effects of single-task versus dual-task training on balance performance in older adults: a doubleblind, randomized controlled trial. Archives of physical medicine and rehabilitation. 2009 Mar 1;90(3):381-7.

8. Bherer L, Kramer AF, Peterson MS, Colcombe S, Erickson K, Becic E (2008). Transfer effects in taskset cost and dual-task cost after dual-task training in older and younger adults: further evidence for cognitive plasticity in attentional control in late adulthood. Exp Aging Res; 34 (3):188-219.

9. Li KZ, Roudaia E, Lussier M, Bherer L, Leroux A, McKinley PA(2010).Benefits of cognitive dualtask training on balance performance in healthy older adults. J Gerontol A Biol Sci Med Sci.65 (12):1344-1352.

10. Silva RJ, Dias SM, Piazza L. Desempenhoematividades de simples e duplatarefas de idososinstitucionalizadosquerealizam e nãorealizamfisioterapia. Fisioterapia e Pesquisa. 2017 Jun;24(2):149-56.

11. Wollesen B, Voelcker-Rehage C. Training effects on motor-cognitive dual-task performance in older adults. European Review of Aging and Physical Activity. 2014 Apr 1;11(1):5-24.

12. $\mathrm{Wu} \mathrm{T}$, Hallett $\mathrm{M}$. The influence of normal human ageing on automatic movements. The Journal of physiology. 2005 Jan 15;562(2):605-15.

13. Verghese J, Kuslansky G, Holtzer R, Katz M, Xue $\mathrm{X}$, Buschke H, Pahor M. Walking while talking: effect of task prioritization in the elderly. Archives of physical medicine and rehabilitation. 2007 Jan 1;88(1):50-3.

14. MoeNilssen R, Nordin E, LundinOlsson L and partly based upon discussions within Work Package 3 of the European Community Research Network Prevention of Falls Network Europe. Criteria for evaluation of measurement properties of clinical balance measures for use in fall prevention studies. Journal of evaluation in clinical practice. 2008 Apr;14(2):236-40

15. Shinar D, Tractinsky N, Compton R. Effects of practice, age and task demands, on interference from a phone task while driving. Accident Analysis \& Prevention. 2005 Mar 1;37(2):315-26.

16. Falbo S, Condello G, Capranica L, Forte R, Pesce C. Effects of physical-cognitive dual task training on executive function and gait performance in older adults: a randomized controlled trial. BioMed research international. 2016. 